\title{
EFEITOS MATERNOS E NEONATAIS DA TERAPIA ANTIRRETROVIRAL COM RALTEGRAVIR EM GESTANTES PORTADORAS DO VÍRUS DA IMUNODEFICIÊNCIA HUMANA.
}

\author{
Vivianne Carvalho de Quaglia e Silva*, Helaine Maria B. P. M. Milanez.
}

\section{Resumo}

Apesar das vantagens importantes que a terapia antirretroviral com o Raltegravir tem mostrado na prevenção da transmissão vertical do HIV, não há grande esclarecimento e conhecimento a respeito dos possíveis efeitos dela sobre a saúde da gestante e do recém-nascido. Este estudo observacional, de coorte, retrospectivo avaliou os efeitos decorrentes da exposição à terapia antirretroviral composta com raltegravir em uma coorte de gestantes soropositivas e recém-nascidos expostos do CAISM-UNICAMP, atendidos no período de 2010 a 2019.

\section{Palavras-chave:}

Raltegravir, Terapia Antirretroviral, Gestantes.

\section{Introdução}

O aumento da proporção de mulheres infectadas pelo HIV em idade reprodutiva reforça a importância de entendermos e manejarmos adequadamente essa infecção durante a gravidez. ${ }^{1}$

No caso de gestantes que não fizeram uso de tratamento antirretroviral (TARV), o esquema inicial preferencial deve sempre incluir três antirretrovirais (ARVs), sendo um deles da classe dos inibidores de integrase (INI) ${ }^{2}$, os quais possuem grande potência no controle da carga viral do HIV. ${ }^{3}$ Entre estes, o Raltegravir (RAL) é o medicamento mais recomendado pelos consensos mais recentes, já que possibilita rápida redução da carga viral. ${ }^{4}$

A meta do tratamento em gestantes é a supressão total da carga viral até o momento do parto, mas ela deve ser sempre ponderada em relação aos riscos dos ARVs para os fetos e efeitos colaterais na mãe. Embora a utilização do RAL tenha grande valor na prevenção da transmissão vertical do HIV, ela é passível de efeitos adversos sobre o organismo da mãe e do recém-nascido.

Há poucos trabalhos que analisaram os efeitos em gestantes e recém-nascidos expostos, e os que o fizeram encontraram informações insuficientes quanto aos desfechos de exposição para que possam ser excluídos riscos. Assim, analisar dados de mulheres grávidas que tiveram exposição na gestação nos irá ajudar a elucidar a real ocorrência de efeitos dessa medicação no binômio mãe e recém-nascido expostos, de modo que seja possível a confirmação do uso seguro do RAL no tratamento de gestantes portadoras do HIV.

\section{Resultados e Discussão}

Para atingir os objetivos do estudo, está sendo estudada uma coorte de gestantes HIV positivas e seus recémnascidos expostos do CAISM-UNICAMP no período de 2010 a 2019.

Até o momento presente, 30 binômios mãe-filho expostos ao RAL durante a gestação foram identificados. Foram analisados seus prontuários de modo a analisar variáveis que incluem idade, escolaridade, cor, estado civil, antecedentes obstétricos, peso, anemia na gestante, hiperlactatotemia na gestante, alteração de enzimas hepáticas na gestante, plaquetopenia na gestante, hiperglicemia na gestante, reação alérgica na gestante, dislipidemia na gestante, comprimento do RN, peso do RN, anemia no RN, hiperlactatotemia no RN, alteração de enzimas hepáticas no RN, plaquetopenia no RN, RN com baixo peso ao nascer, RN com extremo baixo peso ao nascer, RN prematuro.

A idade materna média encontrada foi de 27,4 anos. Entre elas, $43,33 \%$ eram brancas, $40 \%$ pardas e $16,66 \%$ pretas. $83,33 \%$ destas mulheres iniciaram o uso do RAL pela primeira vez durante a gestação. Apenas 16,66\% das gestantes não aceitaram o tratamento e em $10 \%$ dos casos o uso foi suspenso. Foi realizado AZT intraparto em $68,96 \%$ das pacientes.

Foi verificada uma porcentagem de $56,66 \%$ de anemia nas gestantes estudadas, sendo a média da hemoglobina de 10,71. Em 10\% dos casos, também foi constatada alteração de enzimas hepáticas e em 3,33\% houve plaquetopenia e glicemia alterada.

$\mathrm{Na}$ análise dos $\mathrm{RNs}$, o peso médio de nascimento foi de $3048,16 \mathrm{~g}$, o comprimento de $47,28 \mathrm{~cm}$, Apgar de $1^{\circ}$ minuto de 8,5 e de $5^{\circ}$ minuto de 9,56. A taxa de prematuridade foi de $13,3 \%$. Todos RNs receberam AZT oral durante a internação. Houve transmissão vertical em $6,66 \%$ dos casos.

\section{Conclusões}

Como os dados ainda estão sendo levantados, visto que muitos dos casos de 2019 ainda não tiveram desfecho, estamos aguardando uma análise mais completa para que tenhamos conclusões concretas.

1. RAFFE S., CURTIS H., TOOKEY P., PETERS H., FREDMAN A., GILLEECE Y. UK national clinical audit: management of pregnancies in women with HIV. BMC Infectious Diseases. 2017; 17:158.

2. BRASIL. Ministério da Saúde. Departamento de Vigilância, Prevenção e Controle das IST, do HIV/Aids e das Hepatites Virais. Protocolo Clínico e Diretrizes Terapêuticas para Prevenção da Transmissão Vertical de HIV, Sífilis e Hepatites Virais. Brasília, 2017.

3. BOUCOIRAN, I.; TULLOCH, K.; PICK, N. et al. A case series of thirdtrimester raltegravir initiation: Impact on maternal HIV-1 viral load and obstetrical outcomes. Can J Infect Dis Med Microbiol. 2015;26(3):145-150.

4. MALIAKKAL, A.; TSENG, A.; et al. Review of the effi cacy, safety, and pharmacokinetics of raltegravir in pregnancy. J Acquir Immune Defi c Syndr. 2016; 72:153-161 